\title{
A Regional Security Situation Model Based on Space Analysis Technology
}

\author{
Yafei Chen", Huan Zhang, Xiaoyang Luo and Mengsi Wang \\ Institute of Information Technology and Network Security, People's Public Security University of \\ China, Beijing 100076 China. \\ ayafeibios@163.com
}

\begin{abstract}
Keywords: regional security situation, evaluation system, spatial analysis, analytic hierarchy process.
\end{abstract}

\begin{abstract}
Based on the data of GF-2 remote sensing images and GIS, this paper mainly constructs the model of regional security situation. Through the data preprocessing with the remote sensing image processing software, on the basis of the extraction of the information of vegetation, road, and water and housing construction resources, this paper constructs the evaluation index system for the regional security situation by using spatial data analysis technology. Combined with the study of the real situation of regional police information, this paper uses the expert evaluation method to normalize each detailed index, and further uses the analytic hierarchy process to get the weight value of each index. In the grid GIS spatial environment supported by computer technology, the security situation map of the study area is obtained through security indexes. A breakthrough is made when the remote sensing space technology is applied to the public security business. According to the regional security situation map, combined with the field visits in the study area, this paper provides support for the public security affairs by using the research results.
\end{abstract}

\section{Introduction}

In recent years, Chinese government has invested a lot of manpower and financial resources and established emergency response systems in some cities to deal with various problems in securing public safety. Despite the significant results, we found that few areas have applied space technology to emergency response systems[1]. With the development of computer technology and the popularization of remote sensing space technology, this study was equipped with substantial theoretical basis and accurate data support. Through the application of space technology to the public security business, it is found that this method can provide more efficient actual support for the areas where the border areas are sparsely populated.

Security situation refers to the situation that the public security organization, according to a region's possibility of possession of criminals, rationally allocating police resources for patrol and control as well as emergency disposal of public security events. From a technical point of view, in recent years, China's research on public safety is lagging behind that of the developed countries, the results of research are relatively scarce. This study plays a very good supporting role in the study of public safety emergency disposal in China. At present, there are many evaluation system of disaster risk situations at home and abroad. In [2], it establishes the evaluation model of open pit mine landslide by using unascertained measure theory. In [3], it establishes a landslide hazard model by using Logistic regression modeling method, and combines the risk index and vulnerability index to obtain the Lzmir city landslide risk map. The local government department can use it for the initial planning of land use. In [4], it uses the bivariate statistical method to modeling the landslide disaster, the results are applied to the study area and use the data of the landslide location to verify, then they show consistency of the landslide hazard map and landslide location. The results are convenient for future reduction of landslides through rational planning. With reference to the study of disaster risk situation, in the public security operation, the space technology combining remote sensing and GIS is used to carry out security situation research in an important area. It can not only meet the public security organs to combat criminals, but also to maintain the real needs of regional public safety. 


\section{Overview of the Research Area and Research Data}

The study area is the Tarim River Basin, Dunkuotan Township, Yuli County, Bayingolin Mongolian Autonomous Prefecture, Xinjiang Autonomous Region which features a temperate continental climate, has a vast territory and is mainly engaged in agriculture and animal husbandry. According to the expert evaluation method, the four factors of vegetation, water, road and housing construction in this area are the main factors influencing the security situation.

The total area of Dunkuotan Township is 9775 square kilometers of which 16,500 mus are arable land and 178,850 mus grassland. The cotton industry is the leading pillar for vegetation resources. Poplar forest and other forests are lush. The state of $\mathrm{Ba}$ is a lake-rich area with the total lake area of $2398 \mathrm{~km}^{2}$ (excluding Lop Nur and Lake Taitema that have dried up), and it accounted for $43.6 \%$ of the total area of Xinjiang lakes[5]. The rivers flowing through the Yuli County include Konqi River and Tarim River with the average annual rainfall of $43 \mathrm{~mm}$.

In this study, the remote sensing data were derived from the GF-2 satellite which has the characteristics of high radiation precision, high positioning accuracy and fast attitude maneuver ability. The raw data was preprocessed using radiation correction, geometric correction, image fusion, image mosaic and image enhancement of which the image fusion is the fusion of GF-2 image panchromatic wave band (spatial resolution of $1 \mathrm{~m}$ ) with multispectral images (spatial resolution of $4 \mathrm{~m}$ ). GIS is based on a geospatial database to provide an environment for spatial data analysis. Business data was from the police information of regional public security organizations in the study area.

\section{Research Methods}

The research methods of regional security situation model include four steps, (1) extract and analyze the precision of four first-level indexes of vegetation resources, road resources, water resources and housing construction resources after data preprocessing; (2) determine the second-level indexes after refining the first-level indexes using spatial analysis and build a regional security situation evaluation system; (3) use Analytic Hierarchy Process (AHP) to calculate and analyze the weights of the indexes[6]; (4) in the spatial environment of grid GIS, use the security indexes for spatial analysis and get the regional security situation map.

\subsection{Index Extraction and Precision Analysis}

The extraction methods of four indexes of vegetation, road, water and housing construction resources in GF-2 remote sensing images are almost different. The image segmentation and merging scale of the vegetation resources extraction was 50 . The support vector machine classification method was used to classify the study area[7-8]. Based on the ground truth region of interest, a confusion matrix was established. The classification accuracy of the overall classification result was $86.88 \%$ and the Kappa coefficient was 0.823. Based on the classical filtering method, according to the image binaryzation, image segmentation and merging algorithms, the road resources extraction filtered the non-road information. The extraction precision of county road, township road and simple road was $93.1 \%, 76.5 \%$ and $74.0 \%$ respectively. In the extraction of water resources, the Laplacian algorithm was used. After Laplace filter, GF-2 image conducted image binarization, and then segmented and merged. Finally the rule-based object-oriented extraction was implemented. The precision analysis considers the proportion of the correctly extracted water area in the ground real data. The precision of this study was $84 \%$. The extraction method of housing construction resources is similar to that of water resources. Their difference is that the housing construction used the median filter and chose the segmentation and merging scale of 40 . The correct extraction rate of housing construction resources was $87.7 \%$.

\subsection{Construction of the Evaluation Index System}

In this study, $10 * 10$ pixels were used as the grid unit. This study follows rules of objective authenticity, index typicality and index accessibility. The vegetation, road, water area and housing construction resources indexes were refined by spatial data analysis method into the second-level indexes. According to the spatial data analysis method, combining with the actual situation of the 
study area, the evaluation index system of regional security situation is shown in Figure 1 where the classification indexes indicate that the vegetation species in the study area are classified into forest land, farmland, grassland and desert which are calculated by cost distance[9]. The costs of the four types of the vegetation species are 10 for forest land, 3 for farmland, 2 for grassland and 1 for desert.

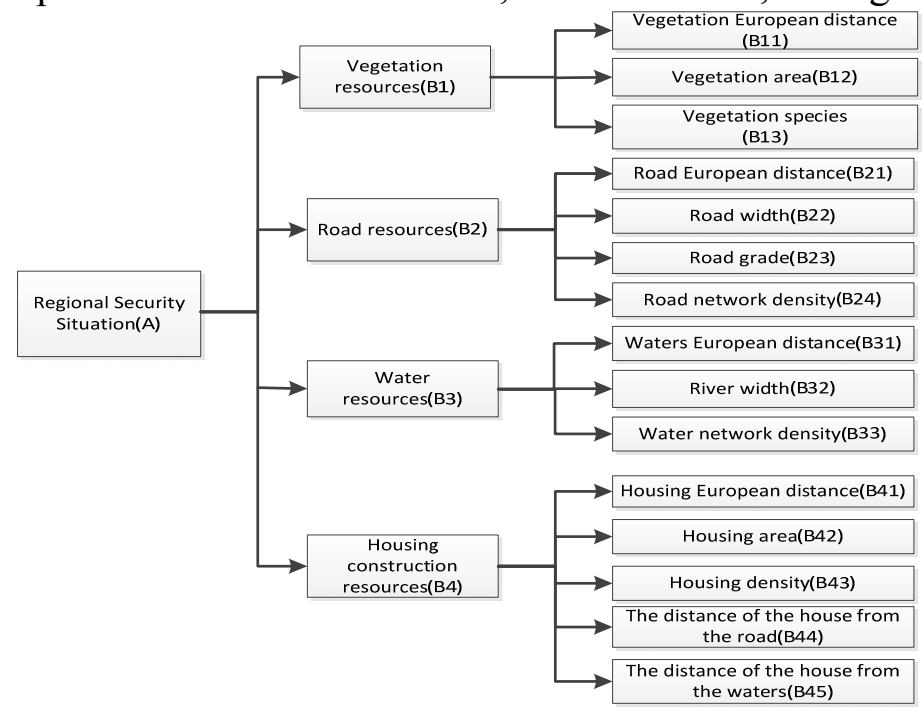

Figure 1 The evaluation index system of regional security situation

The second-level indexes of different dimensions in the index system needed to be normalized to $(0,1)$. The normalized second-level indexes were graded and evaluated by expert evaluation method. The second-level indexes of vegetation resources were used as the example of grading and evaluation, which are shown in Table 1.

Table 1. Graded assignment of second-level indexes

\begin{tabular}{ccccc}
\hline index & \multicolumn{4}{c}{ graded assignment } \\
\hline \multirow{2}{*}{ vegetation continental distance $(\mathrm{m})$} & {$[0,50]$} & $(50,100]$ & $(100,200]$ & $(200,+\infty)$ \\
& 0.45 & 0.3 & 0.2 & 0.05 \\
\hline \multirow{2}{*}{ plant area $\left(\mathrm{km}^{2}\right)$} & {$[0,0.001]$} & $(0.001,0.5]$ & $(0.5,1]$ & $(1,+\infty)$ \\
vegetation species & 0.05 & 0.15 & 0.35 & 0.45 \\
(cost distance) & {$[0,15]$} & $(15,30]$ & $(30,60]$ & $(60,+\infty)$ \\
& 0.05 & 0.25 & 0.3 & 0.4 \\
\hline
\end{tabular}

\subsection{Determination of Evaluation Index Weights}

The determination of the index weights is an important process in the establishment of the security situation model. The determination of the evaluation index weights adopted Analytic Hierarchy Process (AHP). AHP determined the index weights by combining qualitative analysis and quantitative analysis which is suitable for the security situation model with multiple targets and complicated structure[10]. (1) Firstly, the hierarchical structure of AHP was determined by the established regional security evaluation index system. (2) Secondly, in the evaluation index system, the relative importance of each factor was determined by the comparison between the first-level indexes and each refined second-level index to build the judgment matrix[11]. The weight judgment matrix was constructed by scale value $B_{i j}$ or $B_{j i}$. The scale value is the value of relative importance of $B_{i}(\mathrm{i}=0$, $1, \ldots, \mathrm{n})$ to $B_{j}(\mathrm{j}=0,1, \ldots, \mathrm{n})$ indicated by $B_{i j}$. The judgment of matrix element $B_{j i}$ used $1-9$ scale method for relative comparison and estimation of the matrix[12] and the judgment matrix for evaluation index was determined. (3) Finally, using the MATLAB programming, it is easy to obtain the maximum eigenvalue $\lambda_{\max }=4.0458$ and the corresponding eigenvector $W$. After the normalization of $W[13]$, it can be got that the weights of each class index is [ $\left[\begin{array}{lllll}0.1645 & 0.2561 & 0.1077 & 0.4717\end{array}\right]^{\mathrm{T}}$.

Consistency indexes are shown as formula 1:

$$
\mathrm{C}_{1}=\left(\lambda_{\max }-\mathrm{n}\right) /(\mathrm{n}-1)
$$

Substituting the numerical values, the calculation result is $\mathrm{C}_{1}=0.0153$. The randomness index $\mathrm{R}_{1}$ is given in article[14]. It can be seen that the fourth-order matrix $\mathrm{R}_{1}=0.9$. The random consistency ratio is shown in formula 2 :

$$
\mathrm{I}=\mathrm{C}_{1} / \mathrm{R}_{1}
$$


Substituting the numerical values, the calculation result is $\mathrm{I}=0.0170<0.10$. The nonuniformity of the judgment matrix is acceptable. The corresponding eigenvector of $\lambda_{\max }$ can be used as a weight value after normalization (rounded to four decimal places). Similarly, the weight of each index can be determined, as shown in Table 2.

Table 2. Hierarchical Weight

\begin{tabular}{|c|c|c|c|}
\hline $\begin{array}{c}\text { First-level } \\
\text { evaluation index }\end{array}$ & $\begin{array}{l}\text { First-level index total ranking } \\
\text { weight }\left(P_{\mathrm{i}}\right)\end{array}$ & $\begin{array}{l}\text { Second-level } \\
\text { evaluation index }\end{array}$ & $\begin{array}{l}\text { Relative weight } \\
\qquad\left(Q_{i}\right)\end{array}$ \\
\hline \multirow{3}{*}{ B1 } & \multirow{3}{*}{0.1645} & B11 & 0.4673 \\
\hline & & B12 & 0.0954 \\
\hline & & B13 & 0.1601 \\
\hline \multirow{4}{*}{ B2 } & \multirow{4}{*}{0.2561} & B21 & 0.4476 \\
\hline & & B22 & 0.1059 \\
\hline & & B23 & 0.1636 \\
\hline & & B24 & 0.2829 \\
\hline \multirow{3}{*}{ B3 } & \multirow{3}{*}{0.1077} & B31 & 0.5584 \\
\hline & & B32 & 0.1219 \\
\hline & & B33 & 0.3197 \\
\hline \multirow{5}{*}{ B4 } & \multirow{5}{*}{0.4717} & B41 & 0.2332 \\
\hline & & B42 & 0.1480 \\
\hline & & B43 & 0.4440 \\
\hline & & B44 & 0.0753 \\
\hline & & B45 & 0.0995 \\
\hline
\end{tabular}

\subsection{Classification of Security Situation}

In order to quantify the regional security situation, this study used the Security Index (SI) to represent the impact of various indexes on regional security situation. The security index is calculated as follows formula 3:

$$
\mathrm{SI}=(1+\mathrm{H}) * \sum_{i=1}^{m} \mathrm{P}_{\mathrm{i}} *\left(\frac{\sum_{i=1}^{n} \mathrm{f}_{\mathrm{i}} * \mathrm{Q}_{\mathrm{i}}}{100}\right) \quad(\mathrm{m}=4, \mathrm{n}=3,4,3,5)
$$

In the formula, $S I$ denotes the security index, $H$ denotes the probability of the occurrence of a public security event in the grid unit in a certain reference time and $f_{i}$ denotes the hierarchical value of the second-level indexes in the grid unit in the actual calculation. Because decimals can not be used in the Arcgis calculation, the values of the classification evaluation table in the actual operation were amplified to 100 times and removed in the grid calculation formula. $P_{i}$ denotes the ranking weight of each first-level index and $Q_{i}$ denotes the ranking weight of each second-level index. Because the greater the value of the index, the higher the risk, the greater the $S I$, the greater the risk of the region will be. In this study, the security index was normalized to $(0,1)$ and divided into five grades according to the arithmetic method[15]. From the first to the fifth grades, the security indexes gradually increased. The first to the fifth grades were shown in blue, green, yellow, brown and red color in the security situation grade map respectively. The security situation map of the study area based on GF-2 on October, 2016 is shown in Figure 2. 


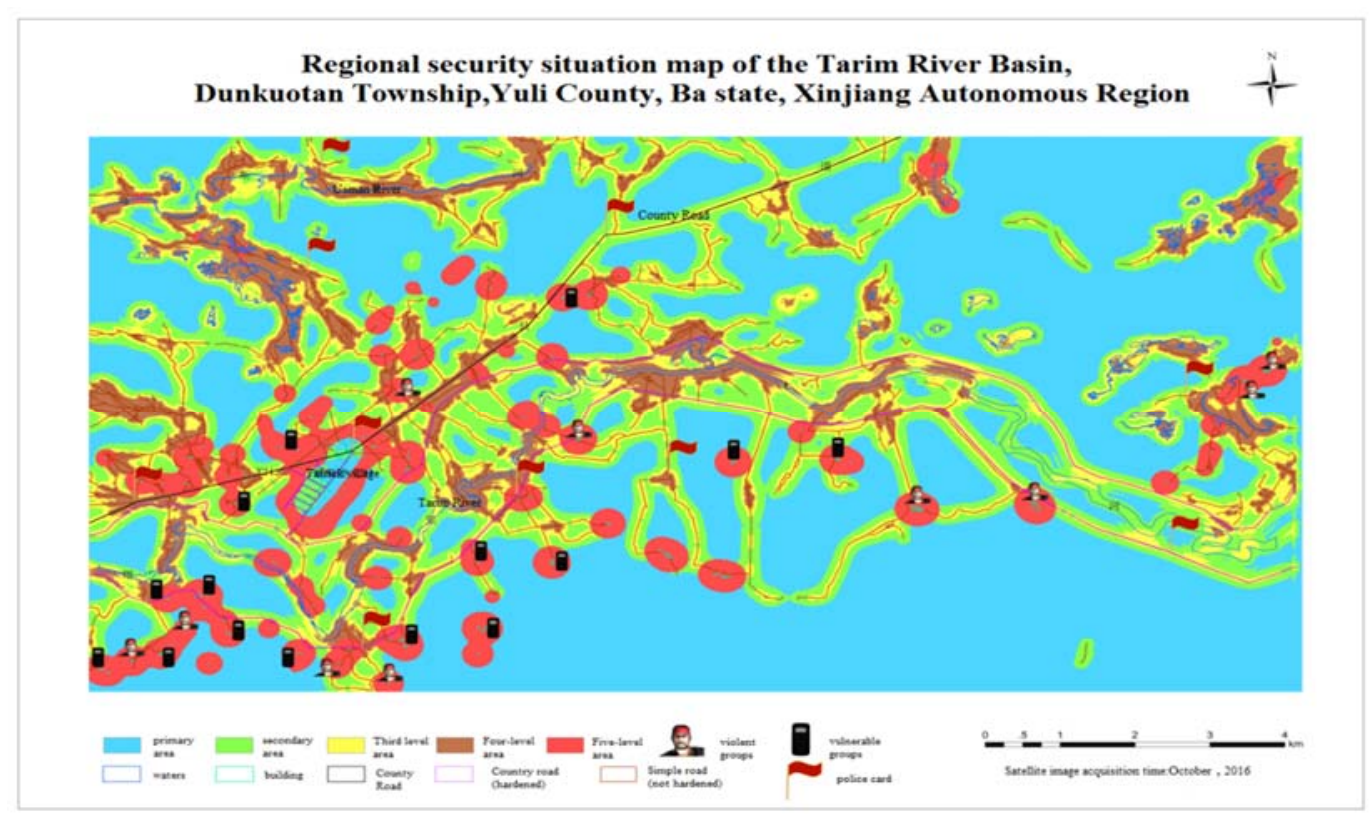

Figure 2. The security situation map of the study area on October, 2016

\section{Conclusion and Outlook}

This study attempts to construct a regional security situation model and introduces the research methods. Based on GF-2 remote sensing satellite image and GIS data, using the spatial data analysis technology, this study built the evaluation index system of regional security situation. Through AHP, the weight of each index was determined. The regional security situation was classified by the security index. A regional security situation map was created, and a regional security situation model was built. This study realizes the goal of providing strong support for public security affairs in the study area. According to the comparison of the regional security situation map in different months, the application of the regional security situation model in the public security operation can be further analyzed, and adjusts the real-time tactics of public security timely.

\section{References}

[1]. Zhong M, Shi C, Fu T, et al. Study in performance analysis of China Urban Emergency Response System based on Petri net[J]. Safety Science, 2010, 48(6):755-762.

[2]. Luan Tingting, Xie Zhenhua, Wu Zongzhi et al. Risk Evaluation Model of Waste Dump Landslide based on Uncertainty Measurement Theory[J]. Journal of Central South University (Science and Technology), 2014.

[3]. Akgun A, Kincal C, Pradhan B. Application of remote sensing data and GIS for landslide risk assessment as an environmental threat to Izmir city (west Turkey)[J]. Environmental Monitoring \& Assessment, 2012, 184(9):5453-5470.

[4]. Radha Raman, Milap Punia. The application of GIS-based bivariate statistical methods for landslide hazards assessment in the upper Tons river valley, Western Himalaya, India[J]. Georisk Assessment \& Management of Risk for Engineered Systems \& Geohazards, 2012, 6(3):1-17.

[5]. Shao Mincheng, Shao Nian, Shen Qiang et al. Dynamic Change and Analysis of Lakes and in Bayingolin Mongolian Autonomous Prefecture, Xinjiang [J]. Arid Zone Research, 2009, 26(3): 318-325.

[6]. Hou Min, Jia Shaohui, Guo Zhaocheng et al. Using RS and GIS -based AHP Technologies for Landslide Hazard Assessment: Taking Tiantai Landslide in Xuanhan County, Sichuan Province as an Example [J]. Geoscience, 2006, 20(4): 668-672.

[7]. Chi M, Feng R, Bruzzone L. Classification of hyperspectral remote-sensing data with primal SVM for small-sized training dataset problem [J]. Advances in Space Research, 2008, 41(11):1793-1799. 
[8]. Liu Wei. Vegetation Information Extraction Based on Layering Technology and SVM Supervised Classification[J]. Software Guide, 2015, 14(10): 160-162.

[9]. Qu Xiaokang, Rui Xiaoping, Han Ying et al. Improved Ant Colony Algorithm for Calculating Grid Cost Distances [J]. Journal of Geo-information Science, 2016, 18(8): 1052-1059.

[10]. Ennaceur A, Elouedi Z, Lefevre E. Belief AHP Method: AHP Method with the Belief Function Framework [J]. International Journal of Information Technology \& Decision Making, 2016, 15(3):553-573.

[11]. Yan Jun, Zhang Zhonghao, Zhou Quan. Planning and Construction Suitability Research based on GIS Overlay Analysis: Taking Life Care and Aging Community in Baiyun Mountain, Xuancheng City as an Example[J]. China Forestry Science and Technology, 2014, 28(5): 131135.

[12]. Hou Lina, Chen Donghai, Peng Guihua. Improvement of AHP and its Application in Sichuan Agricultural Development[J]. Journal of Anhui Agricultural Sciences, 2009, 37(16): 7708-7711.

[13]. Song Fei, Zhao Fasuo. Application of Analytical Hierarchy Process and MATLAB Program for Risk Analysis of Underground Engineering[J]. Journal of Earth Sciences and Environment, 2008, 30(3): 29-296.

[14]. Cai Suozhang. Mathematical Modeling: Principles and Methods[M]. Shandong: Ocean Press, 2000.

[15]. Zheng Yu, Hu Yecui, Liu Yansui et al. Spatial Analysis and Optimal Allocation of Land Resources Based on Land Suitability Evaluation in Shandong Province[J]. Transaction of the CASE, 2005, 21(2): 60-65. 